\title{
Analysis of Romantic Factors in Classical Music
}

\author{
Jiayuan Liu
}

\author{
Musicology Academy of music, Guangdong Polytechnic Normal University, Guangzhou, 510665 \\ Corresponding Author's Email: 920262513@qq.com
}

\begin{abstract}
Classicism is popular in the 17th and 18th centuries of western society, when the European society underwent changes and wars, and the bourgeois regime was overthrown. Due to the outbreak of the Enlightenment and the French Revolution, the society was influenced by the upsurge of cultural thoughts, so was the style of music. During this period, although classicism was characterized by its orderly civilization, humanism and romanticism could be found in the works, and romantic music was in the rudimentary stage.
\end{abstract}

Keywords: Classicism, Enlightenment thought, Humanistic atmosphere, Romantic factors

\section{BACKGROUND OF CLASSICAL MUSIC}

\subsection{Need of the audience}

In the period of Viennese Classicism, intellectuals initiated the Enlightenment and the French Revolution. The outbreak of cultural ideological trend stimulated the national consciousness of people in all European countries. With people's ideological consciousness being constantly awakened and their subjective consciousness being constantly strengthened, they began to pursue the brilliance of rationality and human rights. Influenced by the cultural trend, musicians put more emphasis on human emotions rather than being blindly bound by divinity in their creation, which changed the regular style of music creation and added their own idea during creation, thus enriching the genre of their works. ${ }^{[1]}$ The style of music is no longer as solemn and depressing as it was in the Baroque period, instead, it can express the mood of the citizens. Under the social conditions at that time, people hoped to find some comfort with light and rationality from music, and the music provided by the composers was in line with their emotional appeal to get rid of the previously restricted thoughts, which exactly meets people's need to pursue human rights. Romantic creation was emerging quietly. ${ }^{[2]}$

\subsection{Expression style of music}

Classical style was formed in the middle of the 18th century. Music during the period of classicism can be divided into two periods: the first period is the short rococo period, during which the musical works tended to be orderly and bright, delicate and elegant, with some counterpoints and repeated lines. At this time, most music belongs to the royal court music, which massively adopts counterpoint technique on melody and composition, making musical works orderly and gorgeous; hence, the music at that time presents baroque style.

The second period is the Viennese period, when the cultural trend promoted the prosperity of musical culture. During this period, music is no longer limited to serving the church, but gradually expanding to the citizens. Music works tend to be more popular and folklore, which are splendid, elegant and close to nature, with richer themes, many folk tones, and added dancing elements. ${ }^{[3]}$ Opera flourished at this time, and its creation style was influenced by humanism. In Mozart's opera Don Juan, characters of different classes and personalities were added to reflect people's life through their circumstances. In the meanwhile, there was also his emotional sustenance, which implied romanticism.

\subsection{Connection between the classics and the reality}

Music in the Baroque period intended to let people learn to sing sacred music so as to purify their minds, thus guiding guide people's thoughts and consciousness to the height in line with their religious development, by educating the enlightened the civil class under the leadership of the Pope. However, the so-called "theocracy" was actually seized by the Pope, who preached religion and conducted spiritual brainwashing to the citizens. ${ }^{[4]}$ However, with the continuous development of the society, people have a further understanding of their 
own thoughts. More and more intellectuals stand out to advocate rationality and humanity, and pursue freedom and equality. In the 17th and 18th centuries, the initiation of the Enlightenment and opposition of the people of Paris against long-term oppression resulted in the outbreak of the French Revolution. The intellectuals tried to break the traditional ideas, oppose the feudal autocracy and stimulate people's ideological consciousness. Under the ideological impact, the life of the citizens has changed: they pursued a higher quality of life; and their economic, cultural and educational demands increased.

Under the promotion of ideological emancipation by intellectuals, people's ideological consciousness began to awaken, to pursue for human rights and advocate free democracy thought. The mind of the citizen stratum was gradually liberated, which broke the constraints of feudal system. Advanced culture was spread in the whole of western society. The trend stimulated the creation and development of music, and composers express their feelings directly in his works. It is, in nature, to promote humanism. It is no longer limited to the creation technique during the period of classicism; instead, it can be found that some composers are to place their feelings in their works. The innovation of artistic works is in conjunction with the development of the society. ${ }^{[5]}$

\section{CLASSICAL MUSIC WITH ROMANTIC ELEMENTS}

\subsection{Secularity in Mozart's music}

\subsubsection{Romanticism in operas}

Operas of the romantic period are very dramatic, which express some kind of phenomenon through the metaphor in myth stories. The creation style of music is free, bold and unrestrained. Musicians pour thoughts into music works, daring to make innovations of music. In the works during the reform period of Christoph Willibald Gluck, the classical composer, music melody and plot development are integrated with each other, which increases emotional expressiveness, demonstrates themes, and reforms the structure of lyrical operas, with music playing a big role in operas.

Deeply influenced by Christoph Willibald Gluck, Mozart applied genre of myth in his creation Magic Flute, which alluded to the darkness of the Middle Ages, with the script closer to the Romantic era. The Opera Magic Flute took the trial of the Queen of the Night to rob the
Temple of Light as the theme, to narrate the story that the Queen of the Night used Prince Tamita to rescue his daughter Pamina, who was kidnapped by the villain Sarastro, and recaptured the Sun Mirror. However, in fact, Sarastro is actually the symbol of light. In the process of rescuing Pamina, Tamita experienced all kinds of difficulties and tests, and finally saw through the conspiracy of the Queen of the Night. The story of Magic Flute renders a kind of unrestrained feeling; and the works of Mozart give people a kind of refreshing feeling. The composition of this opera is different from the classical style, but more like the Romantic style, which reflects the beginning of the early Romantic creation. ${ }^{6]}$

The Freemasons are a mystical and powerful organization with some faith power. During this period, they opposed the Catholic Church dictatorship and promoted the revival of humanism. It is said that Mozart was also a member of the Freemasons. The Magic Flute, written by Mozart, to some extent, reflects the real life he encountered. The protagonist of the Queen of the Night is actually a reference to the Empress Maria Austria. Teresa, who persecuted the members of the Freemasons and banned their activities. Mozart expressed the social phenomena through his work, by putting faith in his works. Actually, in the creation of the work, romantic style shows up. During the period of romanticism, composers fully express personal feelings. They reflect real life by means of art, and their music is lyrical and imaginative. During the period of classicism, music works is orderly; however, the music in Magic Flute is not entirely orderly, but penetrated with Mozart's own emotions. Mozart is a member of the Freemasons. Undergoing the Enlightenment, social changes and eight years of humiliation and being enslaved in the palace, Mozart was resistant to the society. His bitterness and passion and hope for the life were all poured into in his works. Even though life was unfair to him, his pursuit of light was endless.

The aria of Magic Flute demonstrates the anger and hatred of the Queen of the Night incisively and vividly. The Queen of the Night forces her daughter to kill Sarastro. The contradiction and conflict are pushed to the peak by the pressing of the Queen of the Night and the despair of her daughter. The climax fully expressed the anger of the Queen of the Night. Strong color is contained in the rising pitches, which implies that Mozart was sad and despair because of the force of life, but after pains and bitterness, the Queen of the Night was punished, with a happy ending, which embodies that although struck in deep abyss, Mozart is still full of hope for the future. ${ }^{[7]}$ 


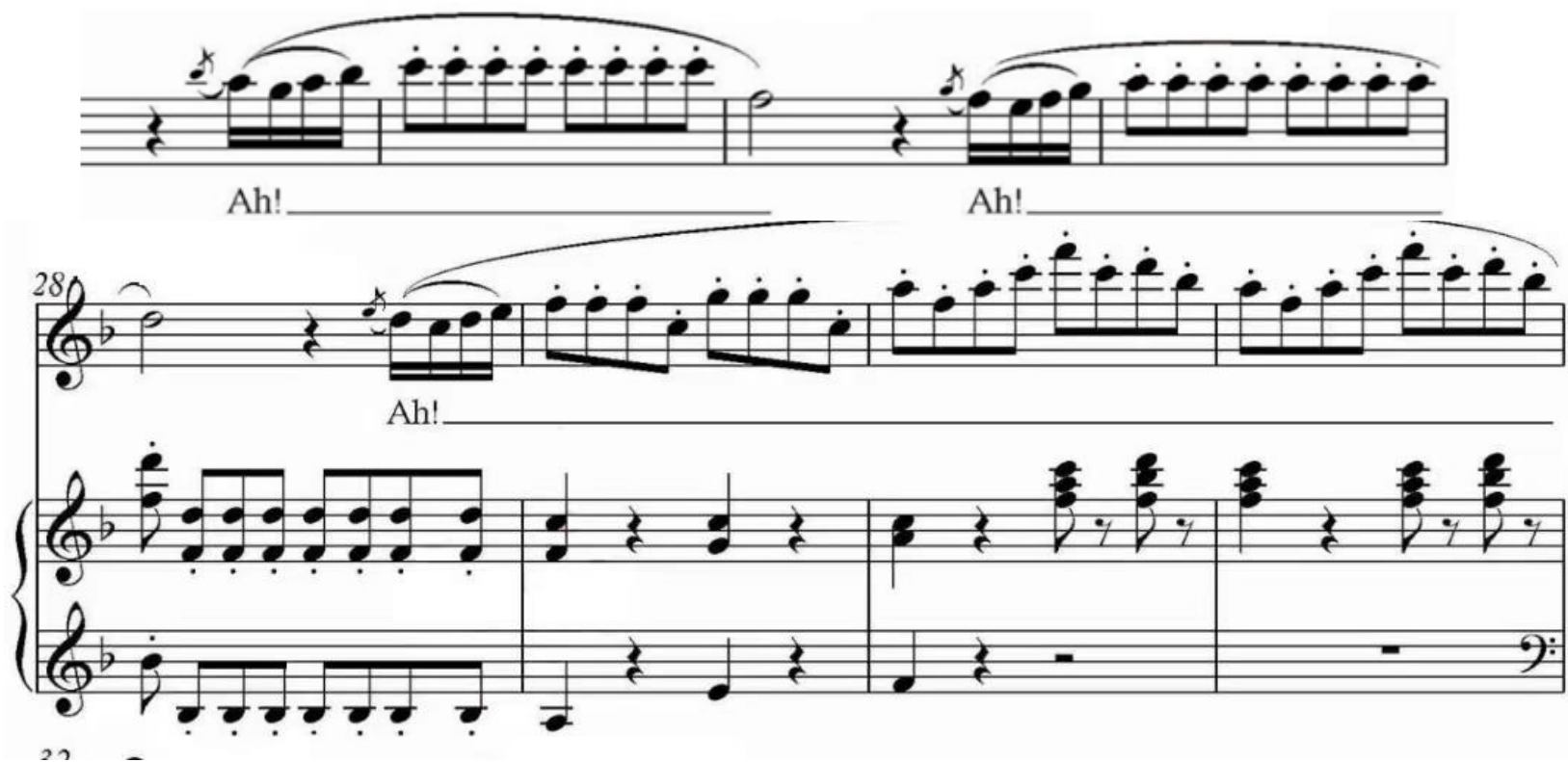

Figure 1. the score of the opera Magic Flute

\subsubsection{Connotation of Instrumental Music Works}

At the age of 17, Mozart worked as a court musician, but was driven at the whim of the archbishop, leading to Mozart's long living in slavery. As his patience had gone out, Mozart left the court and went to Vienna to earn a living. He no longer wrote for the court. Under the impact and continuation of the enlightenment thought, Mozart poured his fantasy of the beautiful life and the bitterness in life into his works. His experience freed his thought from the classical style of composition.

In his later symphonic work Allegro of Symphony No. 40, it can see that his creative style is biased towards the romantic color. The strength and weakness of the melody at the beginning of the music fluctuates greatly, and in the second sentence of the melody, the use of the second modulus and repeated emphasis technique show Mozart's anxiety and depression. The melody of the music brings people a sense of tension. Rapid play of violin gives people the nervous and uneasy sense of feeling, with gloomy acoustics. Although the chord assembler is concise and clear, in four different parts of violin performance, it creates the serious and nervous atmosphere, which vividly reflects Mozart's inner contradictions and struggles at this time. ${ }^{[8]}$

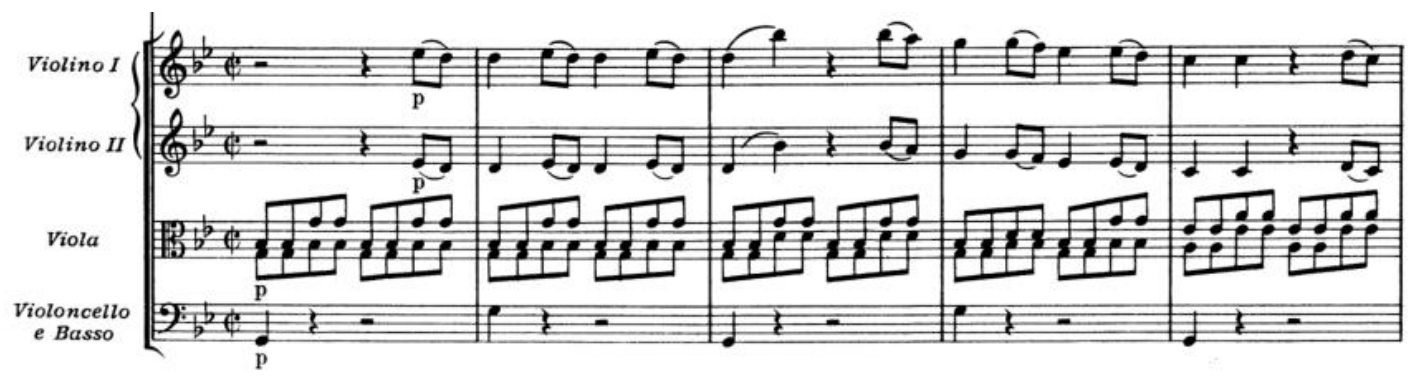

Figure 2. the work of Allegro of Symphony No. 40

After a brief transition, the theme melody reappears. The woodwind and violin are played together, which makes the rhythm more compact. The mixed emotions of passion and melancholy make the work full of vocality and complex emotional changes. The work adopts the technique of creating contradictions first and then solving them. The ups and downs of music and the conflicts of emotions can be seen from the changes of Mozart's works style. He jumped out of the original classical creative technique and gradually changed to the romantic style. 


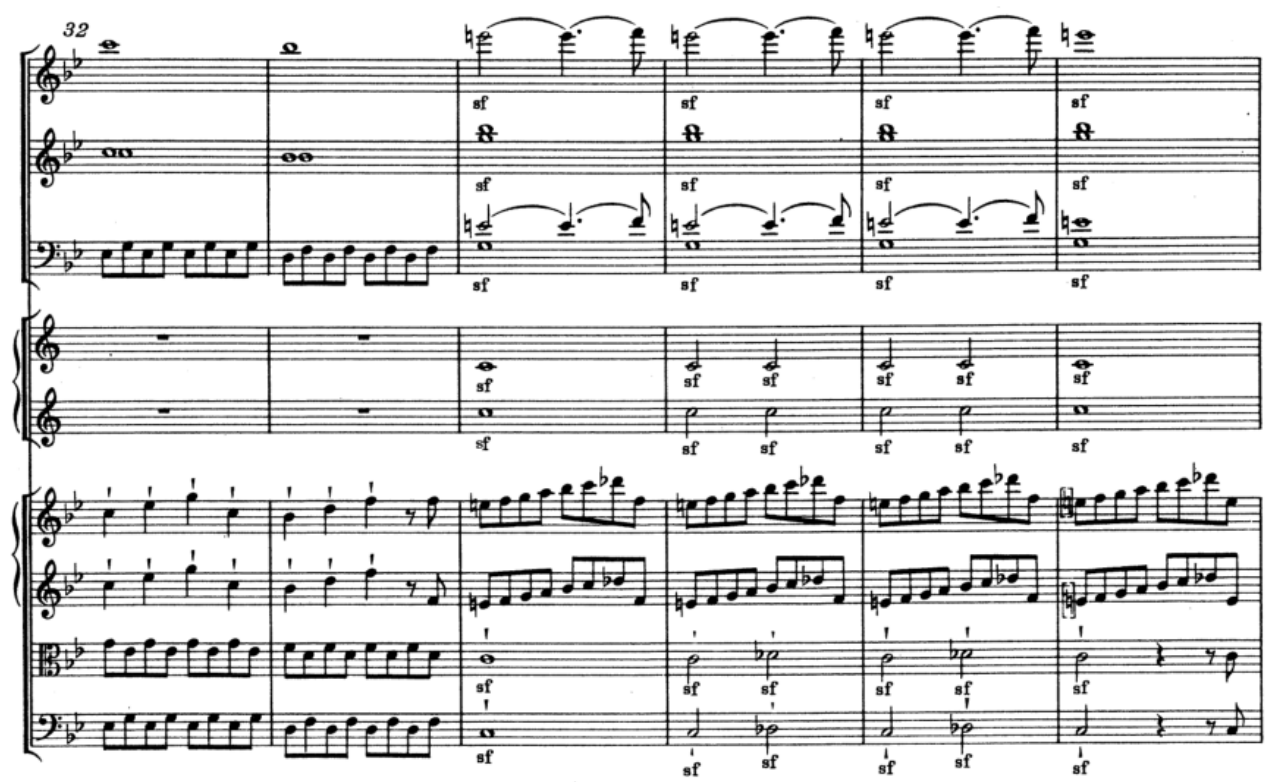

Figure 3 the work of Allegro of Symphony No. 40

\subsection{Heroism in Beethoven's music}

Most of Beethoven's early works fit the characteristics of the classical style at that time, and the structure of his works sticks to rigorous counterpoint. In the 18th century, Germany was in a period of social unrest and political instability, Beethoven was tortured by fate, disease and betrayal, because of which he changed a lot in his character and thought. During this period, Germany started Sturm und Drang, which is a literature liberation movement launched by young intellectuals of the emerging bourgeoisie in the 18th century of Germany. It' $s$ the is enlightenment initiated by the representative of the citizen class, who proposes individual character liberation, advocates perception, opposes to the tyranny of hierarchy in the old days, promotes human rights and pursues freedom and equality. Influenced by Sturm und Drang, the German youth begins to focus on human rights consciousness, and become more endeavoring. ${ }^{[5]}$ To some extent, Beethoven was influenced by Sturm und Drang, which can be seen in his C Minor Allegro of Symphony No. 5, where his style gradually became magnificent after he experienced Sturm und Drang and some setbacks. Although Beethoven suffered a lot of torture, he did not give up and bowed to fate. Instead, he wrote his hope for life into his works. ${ }^{[9]}$

Beethoven changed the usual classicism style, and created unusual music. This work reflects his resistance to fate and indignation after encountering injustice in life, as well as his strong will to struggle with the society, which expresses Beethoven' s heroism of not yielding to fate.
The beginning of the work begins with a short rhythm of several notes, i.e., three short notes and one long notes, which unfolds a tense and tragic atmosphere and reveals the theme. ${ }^{[10]}$ The melody and rhythm of the woodwind and the violin are consistent, and the second bar has a prolonged note mark. The performance of different instruments emphasizes the serious atmosphere, which makes the mood tense and low all of a sudden, and the atmosphere becomes sad. Such a creative technique is not as orderly as it was in the period of classicism, but becomes quite innovative. The design of prolonged notes makes this tension linger in the whole atmosphere, which can clearly reflect Beethoven's pain and despair after being tortured by fate. ${ }^{[11]}$

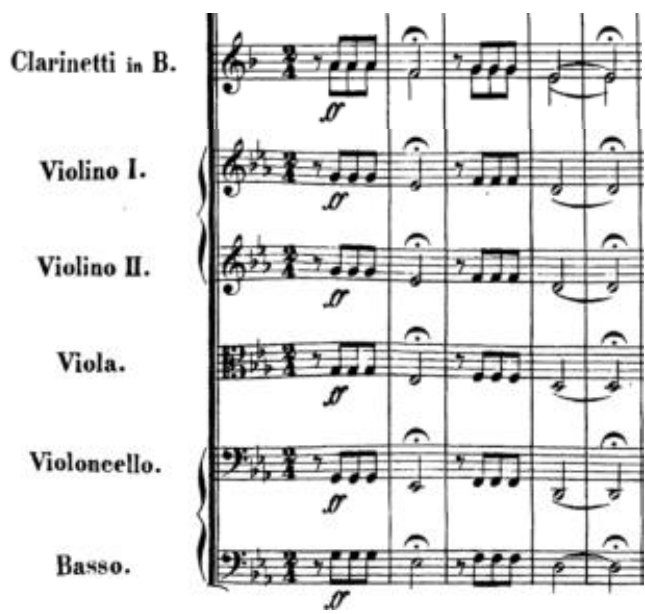

Figure 4. the work of C Minor Allegro of Symphony No. 5 


\section{EXPOUNDING THE REASONS WHY THE ROMANTIC FACTOR EXISTS IN CLASSICAL MUSIC}

\subsection{Development trend of music style}

As for the music style in Early classicism, music is still retained the baroque style, which is concise and clear. Under the theocratic tyranny of the social environment at that time, the music is believed to serve for God, and the existence of music is to sing praises to God, so that classical music is generally created for the appreciation of the court and the noble, with the style rigorous and luxuriant. Under the oppression of the feudal autocratic system in the old society, intellectuals launched the cultural trend of the Enlightenment in Europe. Under the impact of the cultural trend, people no longer believe in deity or God, and change the belief from theocracy to the pursuit of human rights. People gradually have an understanding of their own thoughts. [12] The appeal of the citizen class to music expands, and they hope to place their hopes on music, because music brings redemption to the citizen class, and music can purify people's mind. Under a continuation of the ideology and culture, the composers see the demand of the citizen class, so they try to make some music meeting the taste of citizen class, and the music style gradually becomes diversified and folkloric. The diversification of music style makes music continuously develop. Due to the service objects of music expand, the composers' styles have also changed from the orderly and luxuriant palace music to the music meeting the taste of citizen class. They tried to express their dissatisfaction with the society and the hope of pursuing rational brilliance in their works. They created music that went beyond the rules of classicism, infused ideas into the works, and made innovation in music. Different composers' creative styles lead to the diversification of musical works, which are full of romanticism and promote the prosperity of musical culture.[13]

\subsection{Times transformation of western society}

The Enlightenment and the French Revolution broke out in Europe. The Enlightenment is an ideological liberation movement that intellectuals rebelled against the dark Middle Ages. The French Revolution is the rise of intellectuals against the feudal autocratic system and the criticism of the ruling class's mental control of citizens. The European society in the 18th century was enveloped by theocracy, and the church and the aristocracy held the power. Under their leadership, the old society was in decline and lifeless, where people lived like puppets. Their clothing, food, shelter, transportation and even education were controlled by theocracy, and the civil class was ignorant and could not see the light. Because the society was oppressed by the feudal autocratic system for a long time, the intellectuals' aversion to the dark life and desire for the light inspired the outbreak of the Enlightenment. [14] Headed by Rousseau, Voltaire, and Montesquieu etc., liberation movement, i.e. the Enlightenment was launched. The main purpose of the Enlightenment was to oppose the idea that people had long been bound by so-called theocratic religious beliefs. In order to awaken the thoughts of the citizen class, the Enlightenment thinkers advocated human emotion, promoted rationalism, and pursued freedom and equality. After the awakening and resistance of the citizens, the social life has been changed and the social hierarchy has been weakened. The citizens win certain social status and then they can enjoy the spiritual power brought by music.

\subsection{Influence of humanism atmosphere}

Under the influence of social upsurge, the musicians in the classicism period added their own fantasy to their works. Subjective consciousness made them endue the hope of life in their works. During the Vienna period, the whole society began to affirm the status of "man", and the humanistic color was added in all kinds of literature and art works. As can be seen from the musical works listed above, composers express their emotions, and reflect or dream about the real world. The musical thoughts of the works have been tinged with romantic tones, and the ideology of romantic creation emerged during this period. During this period, the ideology of romantic creation emerged. At the end of his life, Mozart only took six weeks to compose three symphonies. Even though they were commissioned by others, but they were well received by the citizens. These three symphonies are the Symphony No.39, Symphony No.40 and Symphony No.41 respectively. The distinctive style of each symphony is not completely in line with the classical style of that time. During creation, Mozart added his own thoughts. His Symphony No.39 is as known as "swan song", symbolizing his optimism and hope for the life. The Symphony No.40 is also full of enthusiasm. Even though Mozart's life was very hard at that time, he still wanted to write in his works. The Symphony No.41 is heavy and tense. It can be seen that Mozart's mood was complex and depressed when he created it. The composer's emotional fluctuations have already appeared in the works.

\section{CONCLUSION}

The creative style of composers isn't fixed to create the special kind of music in the exact period. Man has subjective consciousness and can be affected by the environment. The composition of works is based on the composers themselves. The turbulent western society in the 18th century inspired people to pursue freedom and the ideal of life. The generation of music art is the refinement of life, and the lyricism in the works must be one of the products of historical development. 


\section{REFERENCES}

[1] History of Western Music and Appreciation of Famous Works [M]. People's Music Publishing House, Feng Zhiping, 2006.

[2] History of European Music [M]. People's Music Publishing House, Zhang Hongdao, 1983.

[3] Appreciation of Western Cultural History [M]. Shanghai Foreign Language Education Press, Ye Shengnian, 2002.

[4] General History of Western Music [M]. Shanghai Music Publishing House, Yu Runyang, 2003.

[5] Discussion on the Influence of "Enlightenment Movement" on Viennese Classical Music [J]. Wang Bing, $\mathrm{Xu}$ Jie. Journal of Tonghua Normal University. 2006(05).

[6] Appreciation of Mozart's Art Songs [J]. Liu Kai. Time Literature (first half of the month). 2009(02).

[7] A Preliminary Study on the Artistic Characteristics of Mozart's Opera "Magic Flute" [D]. Tang Mengmeng. Qufu Normal University. 2006.

[8] Problems about the Changes of Speed and Rhythm in Music Performance [J]. Yang Li. Journal of the Central Conservatory of Music. 2002(02).

[9] Beethoven and Romantic Music [J]. Chen Yu. Popular Literature. 2012 (01).

[10] Romantic Factors in Beethoven's Piano Sonatas from the Angle of Composition Technique [D]. Liu Bizhen. Hunan Normal University. 2011.

[11] From Classical to Romantic -- On Beethoven's Symphony [J]. Hu Mingzhao. Music Space. 2012(01).

[12] On the Creative Characteristics of Piano Music in the Period of Romanticism[J]. Chen Fang. Chinese Music. 2004 (03).

[13] Double Breakthroughs in Beethoven's Symphonic Composition [D]. Zhao Minqi. Northwest Normal University. 2016.

[14] Romance Sprout under Classical Inheritance [D]. Li Yun. Henan University. 2014. 